design of the trial, analysis of the results, or reporting of the findings.

Competing interests: VJP, RMW, JER, and several of the dietitians involved in this study have previously received travel expenses to attend conferences from the following manufacturers of oral protein energy supplements: SHS International, Liverpool, UK; Ross Laboratories, IL, USA; Nutricia, Trowbridge, UK; Nestle UK, Croydon.

Ethical approval: Ethical approval was granted by the North West Multi-centre Research Ethics Committee and by the local research ethics committees of all the collaborating centres.

1 FitzSimmons SC. The changing epidemiology of cystic fibrosis.J Pediat 1993;122:1-9.

2 Steinkamp G, Wiedemann B. Relationship between nutritional status and lung function in cystic fibrosis: cross sectional and longitudinal analyses from the German CF quality assurance (CFQA) project. Thorax 2002:57:596-601.

3 Peterson ML, Jacobs DR Jr, Milla CE. Longitudinal changes in growth parameters are correlated with changes in pulmonary function in parameters are correlated with changes in pulmonary funct
children with cystic fibrosis. Pediatrics 2003;112(3 pt 1):588-92.

4 Konstan MW, Butler SM, Wohl ME, Stoddard M, Matousek R, Wagener JS, et al. Growth and nutritional indexes in early life predict pulmonary function in cystic fibrosis. J Pediatr 2003;142:624-30.
5 Zemel BS, Jawad AF, FitzSimmons S, Stallings VA. Longitudinal relationship among growth, nutritional status, and pulmonary function in ship among growth, nutritional status, and pulmonary function in
children with cystic fibrosis: analysis of the Cystic Fibrosis Foundation children with cystic fibrosis: analysis of the Cystic Fition
national CF patient registry. J Pediatr 2000;137:374-80.

6 Sinaasappel M, Stern M, Littlewood J, Wolfe S, Steinkamp G, Heijerman $\mathrm{HG}$, et al. Nutrition in patients with cystic fibrosis: a European consensus. J Cyst Fibros 2002;1:51-75.

Smyth R, Walters S. Oral calorie supplements for cystic fibrosis. Cochrane Database Syst Rev 2000;(2):CD000406.

8 Committee on Medical Aspects of Food Policy. Dietary reference values for food energy and nutrients for the United Kingdom. London: Department of Health, 1991.

9 Boucher GP, Lands LC, Hay JA, Hornby L. Activity levels and the relationship to lung function and nutritional status in children with cystic fibrosis. Am J Phys Med Rehabil 1997;76:311-5.

10 Stead RJ, Skypala I, Hodson ME, Batten JC. Enteric coated microspheres of pancreatin in the treatment of cystic fibrosis: comparison with a standard enteric coated preparation. Thorax 1987;42:533-7

11 Cole TJ, Freeman JV, Preece MA. British 1990 growth reference centiles for weight, height, body mass index and head circumference fitted by maximum penalised likelihood. Stat Med 1998;17:407-29.

12 Westerterp KR, Goris AHC. Validity of the assessment of dietary intake: problems of misreporting. Curr Opin Clin Nutr Metab Care 2002;5:48993.

(Accepted 6 January 2006)

doi 10.1136/bmj.38737.600880.AE

\title{
Applicability to primary care of national clinical guidelines on blood pressure lowering for people with stroke: cross sectional study
}

Jonathan Mant, Richard J McManus, Rachel Hare

\begin{abstract}
Objective To compare the characteristics of patients with cerebrovascular disease in primary care with those of the participants in the PROGRESS trial, on which national guidelines for blood pressure lowering are based.

Design Population based cross sectional survey of patients with confirmed stroke or transient ischaemic attack.

Setting Seven general practices in south Birmingham, England.

Participants All patients with a validated history of stroke $(n=413)$ or transient ischaemic attack $(n=107)$ Main outcome measures Patient characteristics: age, sex, time since last cerebrovascular event, blood pressure, and whether receiving antihypertensive treatment.

Results Patients were 12 years older than the participants in PROGRESS and twice as likely to be women. The median time that had elapsed since their cerebrovascular event was two and a half years, compared with eight months in PROGRESS. The systolic blood pressure of 315 (61\%) patients was over $140 \mathrm{~mm} \mathrm{Hg}$, and for 399 (77\%) it was over $130 \mathrm{~mm} \mathrm{Hg}$. One hundred and forty seven (28\%) patients were receiving a thiazide diuretic, and $136(26 \%)$ were receiving an angiotensin converting enzyme inhibitor. Conclusions Important differences exist between the PROGRESS trial participants and a typical primary care stroke population, which undermine the applicability of the trial's findings. Research in appropriate populations is urgently needed before
\end{abstract}

the international guidelines are implemented in primary care.

\section{Introduction}

International guidelines stress the importance of lowering blood pressure in people who have had a stroke. ${ }^{1-4} \mathrm{In}$ the United Kingdom, for example, the national clinical guidelines for stroke recommend a target blood pressure of 140/85 mm Hg and that further lowering of blood pressure beyond this target should be aimed for by using a thiazide diuretic and an angiotensin converting enzyme inhibitor. ${ }^{1}$ The British Hypertension Society guidelines are more aggressive, recommending a target blood pressure of 130/80 mm Hg. ${ }^{2}$ The guidelines are heavily influenced by the PROGRESS trial, which recruited people with stroke from hospital settings. ${ }^{5}$ Despite some debate about the implementation of these research findings regarding which drugs should be used, ${ }^{6}$ a question that has been neglected is whether these guidelines are relevant to primary care, which is where most treatment of blood pressure occurs. We aimed to compare the characteristics of people who have had a stroke in primary care with those of the PROGRESS trial participants.

\section{Methods}

We recruited seven practices active in research from the South Birmingham Primary Care Trust. The practices had a population of 37000 and were selected to

This article was posted on bmi.com on 24 February 2006: http://bmj.com/cgi/doi/10.1136/bmj.38758.600116.AE
Editorial by Mickan and Askew

Department of Primary Care and General Practice, Primary Care, University of Birmingham Birmingham B15 2T1 Jonathan Mant clinical senior lecturer Richard J McManus clinical senior lecturer

Rachel Hare research fellow Correspondence to: J Mant j.w.mant@ bham.ac.uk BMJ 2006;332:635-7 


\section{What is already known on this topic}

National and international guidance emphasises the importance of lowering blood pressure in people with a history of cerebrovascular disease, largely on the basis of the results of the PROGRESS trial

The applicability of the findings of PROGRESS to primary care is uncertain

\section{What this study adds}

Important differences exist between the participants in PROGRESS and a typical primary care population of people with cerebrovascular disease, undermining the applicability of the research findings

represent both a range of practice sizes and areas of low and high deprivation. The study population comprised patients registered with these practices in 2002 who had had a confirmed stroke or transient ischaemic attack. We identified possible participants from three sources: general practice computer systems, a validated postal questionnaire to people aged 65 or over, and a search of a computer system covering all hospital trusts in the south Birmingham area. ${ }^{7} \mathrm{We}$ accepted a diagnosis of transient ischaemic attack as confirmed if a specialist had made it. We accepted a diagnosis of stroke as confirmed if it had been identified from at least two sources or we found definite evidence of stroke in the patient's records. Data on last recorded blood pressure and prescribed drugs came from the general practice computer systems.

\section{Results}

In this primary care population, 413 patients had a history of confirmed stroke, and 107 patients had a history of confirmed transient ischaemic attack (overall prevalence of cerebrovascular disease 1.4\%). The table shows the characteristics of these patients compared with the participants in the PROGRESS trial. In the primary care population, the proportion of women was higher, patients were on average 12 years older, and they had had their most recent cerebrovascular event about two years less recently than the PROGRESS participants. Similar proportions in the two populations had had a transient ischaemic attack but no stroke. Systolic blood pressure was similar in the two populations, but the PROGRESS population had higher diastolic blood pressure, a higher proportion with blood pressure $\geq 160 / 90 \mathrm{~mm} \mathrm{Hg}$, and a lower proportion receiving antihypertensive drugs.

Characteristics of patients in primary care with history of cerebrovascular disease and participants of PROGRESS trial

\begin{tabular}{|c|c|c|c|}
\hline \multirow[b]{2}{*}{ Characteristics } & \multicolumn{2}{|c|}{ Primary care $(n=520)$} & \multirow{2}{*}{$\begin{array}{l}\text { PROGRESS trial } \\
(\mathrm{n}=6105)\end{array}$} \\
\hline & Value & $95 \% \mathrm{Cl}$ & \\
\hline Mean (SD) age (years) & $76(10)$ & 75 to 77 & $64(10)$ \\
\hline Median (IQR) time since last event (years) & $2.5(1-8)^{*}$ & & $0.7(0.2-1.75)$ \\
\hline$\%$ (No) women & $54(282)$ & 50 to 58 & 30 \\
\hline$\%$ (No) with history of TIA only & $21(107)$ & 17 to 24 & 22 \\
\hline Mean (SD) systolic BP (mm Hg) & $148 \dagger(21)$ & 147 to 150 & $147(19)$ \\
\hline Mean (SD) diastolic BP $(\mathrm{mm} \mathrm{Hg})$ & $80 \dagger(12)$ & 79 to 81 & $86(11)$ \\
\hline$\%$ (No) with hypertension (BP $\geq 160 / 90 \mathrm{~mm} \mathrm{Hg}$ ) & $38(188) \dagger$ & 34 to 42 & 48 \\
\hline$\%(\mathrm{No})$ receiving antihypertensive treatment & $68(352)$ & 64 to 72 & 50 \\
\hline
\end{tabular}

$\mathrm{BP}=$ blood pressure; IQR=interquartile range; $\mathrm{TI} A=$ transient ischaemic attack.

*Data available for $419(81 \%)$ patients.

†No blood pressure reading for 23 patients.
The systolic blood pressure of $63 \%(n=315)$ of stroke patients was above the $140 \mathrm{~mm} \mathrm{Hg}$ target, and for $80 \%$ (399) of patients it was over the British Hypertension Society $130 \mathrm{~mm} \mathrm{Hg}$ target. Diastolic blood pressure was better controlled, with 58\% (290) of patients on or below the $80 \mathrm{~mm} \mathrm{Hg}$ target. The blood pressure of $81(16 \%)$ patients was at or below the 130/80 mm Hg target. Sixty eight per cent (352) of patients were receiving at least one antihypertensive drug, and 35\% (181) were receiving at least two drugs. Twenty eight per cent (147) of patients were receiving a thiazide diuretic, but only $1 \%$ (5) were receiving indapamide. Similarly, 26\% (136) of patients were receiving an angiotensin converting enzyme inhibitor, but only $2 \%(9)$ were on perindopril. Forty four $(8 \%)$ patients were receiving both an angiotensin converting enzyme inhibitor and a thiazide diuretic.

\section{Discussion}

The population with prevalent cerebrovascular disease in primary care is very different from the participants in the PROGRESS trial. Current practice is at variance with the guidelines. Patients taking part in clinical trials are well recognised to be different from those seen in clinical practice. In many cases this does not matter, but in the case of blood pressure lowering after stroke it does, as the differences are so great as to undermine the applicability of the research to primary care. The high mean age of patients with a history of cerebrovascular disease in primary care is a cause for concern: over the age of 80 , reduction in risk of stroke through lowering blood pressure may be offset by an increase in mortality. ${ }^{8}$ The longer time lapse since the most recent cerebrovascular event in patients in primary care is also important, as risk of recurrence declines over time, ${ }^{9}$ and the harm to benefit ratio from aggressive treatment becomes less favourable.

A particular strength of this study is that, although drawn from primary care, only patients in whom the diagnosis of cerebrovascular disease had been validated were included. This side steps the problem that recording of cerebrovascular disease on computer in primary care is prone to error with respect to both false positive and false negative diagnoses. ${ }^{7}$

The population is also representative: south Birmingham has similar demographics and mortality from stroke to England and Wales as a whole. Sixteen per cent of the study population were over the age of 65 , which is the same proportion as the national average $^{10}$; the stroke mortality for this area $(2.36 / 10000$ aged under 75) is similar to the national rate $(2.56 / 10000) .^{10}{ }^{11}$ Other studies confirm that the "typical" stroke patient in general practice is very different from the PROGRESS study population. The health survey for England reported that only 17\% of people with stroke had had the event within the previous year, ${ }^{12}$ and analysis of the general practice research database showed that $52 \%$ of prevalent stroke cases are in women. ${ }^{13}$ No previous studies of prevalent stroke have reported mean age, but in the general practice research database analysis $48 \%$ of people with stroke were over the age of $75,{ }^{13}$ and in the OXVASC study $52 \%$ of first strokes were in people over the age of $75 .{ }^{14}$ 
As the practices selected were active in research, blood pressure control in these practices may be better than in the UK as a whole. Our analysis was based on the latest blood pressure recorded in the general practice records. This will have reflected several recordings of blood pressure in some cases and a single reading in other instances. This may have resulted in an overestimation of "true" blood pressure in this stroke population compared with measurements in the controlled setting of a study, but these are the readings on which management will be decided.

Current national and international guidelines may give appropriate advice for the management of blood pressure of younger patients who have had a recent cerebrovascular event. Unfortunately, these guidelines may act as an impediment to further research. We would urge that further evidence should be collected on the efficacy and adverse effects of intensive blood pressure lowering in representative populations before we implement this guidance in primary care.

Contributors: JM conceived and designed the study and analysed the data. RMcM assisted in the design and analysis and supervised the data collection from practices. $\mathrm{RH}$ was responsible for data collection. All authors contributed to the drafting of the paper. JM is the guarantor.

Funding: The research was supported by the Stroke Association. $\mathrm{RMcM}$ was funded by a Department of Health national primary care researcher development award.

Competing interests: None declared.

Ethical approval: South Birmingham Local Research Ethics Committee approved the study.
1 Intercollegiate Stroke Working Party. National clinical guidelines for stroke. 2nd ed. London: Royal College of Physicians of London, 2004.

2 Williams B, Poulter NR, Brown MJ, Davis M, McInnes GT, Potter JF, et al. Williams B, Poulter NR, Brown MJ, Davis M, McInnes GT, Potter JF, et al.
Guidelines for management of hypertension: report of the fourth working party of the British Hypertension Society, 2004-BHS IV. J Hum Hypertens 2004;18:139-85.

3 Chalmers J, Todd A, Chapman N, Beilin L, Davis S, Donnan G, et al. International Society of Hypertension (ISH): statement on blood pressure lowering and stroke prevention. J Hypertens 2003;21:651-63.

4 Chobanian AV, Bakris GL, Black HR, Cushman WC, Green LA, Izzo JL Jr, et al. Seventh report of the Joint National Committee on Prevention, Detection, Evaluation, and Treatment of High Blood Pressure. Detection, Evaluation, and
Hypertension 2003;42:1206-52.

5 Hypertension 2003;42:1206-52. based blood pressure lowering regimen among 6,105 individuals with a previous stroke or transient ischaemic attack. Lancet 2001;358:1033-41.

6 Wennberg R, Zimmermann C. The PROGRESS trial three years later: time for a balanced report of effectiveness. BMJ 2004;329:968-71.

7 Mant J, McManus RJ, Hare R, Mayer P. Identification of stroke in the community: a comparison of three methods. $\mathrm{Br} J$ Gen Pract 2003;53:520-4.

8 Guevffier F, Bulpitt C, Boissel JP, Schron E, Ekbom T, Fagard R, et al. Antihypertensive drugs in very old people: a subgroup meta-analysis of randomised controlled trials. Lancet 1999;353:793-6.

9 Lovett JK, Dennis MS, Sandercock PAG, Bamford J, Warlow CP, Rothwell PM. Very early risk of stroke after a first transient ischaemic attack. Stroke 2003;34:e138-42.

10 National Statistics. Mortality statistics: cause. London: Stationery Office, 2000. (Series DH2 No 26.)

11 West Midlands Public Health Observatory. Key health data for the West Midlands, 2001. Birmingham: Department of Public Health and Epidemiology, 2002. (Report No 31.)

12 Sproston K, Primatesta P, eds. Health survey for England 2003. Volume 1: cardiovascular disease. London: Stationery Office, 2004.

13 Office for National Statistics. Key health statistics from general practice 1998. London: Stationery Office, 2000.

14 Rothwell PM, Coull AJ, Giles MF, Howard SC, Silver LE, Bull LM, et al. Change in stroke incidence, mortality, case-fatality, severity, and risk factors in Oxfordshire UK from 1981 to 2004 (Oxford vascular study). Lancet 2004;363:1925-33.

(Accepted 10 January 2006)

doi 10.1136/bmj.38758.600116.AE

\title{
Intramuscular gluteal injections in the increasingly obese population: retrospective study
}

\author{
Andrew Charles Nisbet
}

\begin{abstract}
Aims To examine depth of subcutaneous fat at gluteal intramuscular injection sites.

Design Retrospective study.

Setting General hospital.

Participants 100 consecutive adults who had computed tomography of the pelvis.

Main outcome measures Minimum distance between the surface of the skin and the nearest edge of muscle at intramuscular injection sites.

Results 12 patients had a ventrogluteal site depth of more than $35 \mathrm{~mm}$, the maximum depth of a green needle, and 26 had a ventrogluteal depth of more than $25 \mathrm{~mm}$, the maximum depth of a blue needle. 43 patients had a dorsogluteal site depth of more than $35 \mathrm{~mm}$, and $72 \mathrm{had}$ a dorsogluteal depth of more than $25 \mathrm{~mm}$. The intramuscular site was likely to be deeper in women.

Conclusion Standard green and blue needles do not reach the gluteal muscles in a considerable number of patients.
\end{abstract}

\section{Introduction}

Studies of intramuscular injections have shown differences in peak plasma concentrations of narcotics and in perceived pain relief, depending on gluteal or deltoid injection site. ${ }^{1}$ Response levels to vaccination vary according to intramuscular injection site. ${ }^{2}$ Different responses depending on site have also been noticed for injections of antibiotics, ${ }^{3}$ insulin, and lignocaine. $^{4}$

Possible reasons for this variation in efficacy include different ratios of adipose to lean muscle tissue, greater blood flow in deltoid than gluteal muscle, ${ }^{5}$ and positional external compression of the gluteus. In a population that is increasingly overweight, these factors could become more exaggerated, leading overall to less effective intramuscular gluteal injections. Additionally, if the depth of fat is so great that the needle cannot reach the muscular layer in many patients, the average absorption of the drug in the population will be lower.

\section{Method}

Scans from 100 consecutive adults (39 men, 61 women; mean 47.8 (SD 11.3) years; range $22-65$ years) who had computed tomography scans of the pelvis

This article was posted on bmj.com on 8 March 2006: http://bmj.com/cgi/doi/10.1136/bmj.38706.742731.47
Jersey General Hospital, St Helier, Jersey JE2 3QS Andrew Charles Nisbet senior house officer in anaesthetics

Correspondence to: Le Grupe, Les Grupieaux, St Peter, Jersey JE3 7ED kaltarn@yahoo.co.uk

BMJ 2006;332:637-8 